Article

\title{
Research on the Pricing Strategy of "Internet + " Recycling Platforms in a Two-Sided Network Environment
}

\author{
Xiaodong Zhu ${ }^{1,2}$ and Wei $\mathrm{Li}^{3, *(D)}$ \\ 1 School of Management Engineering, Nanjing University of Information Science and Technology, \\ Nanjing 210044, China \\ 2 Development Institute of Jiangbei New Area, Nanjing 210044, China \\ 3 Chang Wang School of Honors, Nanjing University of Information Science and Technology, \\ Nanjing 210044, China \\ * Correspondence: 1wnuist@nuist.edu.cn; Tel.: +86-025-58699830
}

Received: 20 December 2019; Accepted: 27 January 2020; Published: 30 January 2020

\begin{abstract}
Internet + " platform recycling is an emerging business model with two-sided market characteristics. How to meet the needs of consumers and manufacturers and how to formulate a reasonable two-sided pricing structure have become challenges faced by recycling trading platforms. Based on the theory of a two-sided market, the pricing mechanism of a monopoly platform and a model of competing platforms are studied. Consequently, a sensitivity analysis and comparison analysis are conducted, giving a pricing decision and the optimal profit of closed-loop supply chain systems. Finally, through a numerical simulation analysis, the impacts of the inter-group network externalities, service differentiation, and the matching efficiency on e-waste recycling prices and profits are obtained. The result indicates that the influences of inter-group network externalities on monopoly platforms and competing platforms are different; thus, platforms should choose pricing strategies according to their own market position. The pricing of the two types of platform is inversely proportional to the time-sensitive coefficient of the two platforms, while it is directly proportional to the matching efficiency. The improvement of the differentiation of service will increase the pricing of the platform for single-homing manufacturers without affecting the multi-homing consumers, and profits will increase accordingly.
\end{abstract}

Keywords: two-sided market; inter-group network externality; closed loop supply chain; game theory; remanufacturing

\section{Introduction}

With the rapid development of science and technology and the wide application of electronic products, electronic waste ushered in large-scale "decommissioning," followed by the recycling of such waste. This has become a hot topic in the industry. In 2016, the world produced 44.7 million metric tons of e-waste, and experts predict that global e-waste will increase by $17 \%$ to 55.2 million metric tons by 2021. Only 20\% of e-waste can be recycled through proper and formal channels [1,2]. At present, self-employed people and small enterprises are still recycling electronic waste in scattered and messy ways in most countries. This kind of recycling not only has an extensive business model, but is also difficult to manage, resulting in unsatisfactory recycling treatment. The traditional trading pattern of the electronic waste recycling industry is badly in need of expansion into new fields.

In the 2015 Circular Economy Promotion Plan, the National Development and Reform Commission of China pointed out that it is necessary to promote and guide recycling mode innovation and explore the "Internet + recycling" mode and path. In this context, a number of emerging "Internet +" recycling 
trading platforms have emerged in China, such as Taolv.com, Aihuishou, and Dafeng. Such platforms are based on the two-sided market theory, with one side connecting consumers who voluntarily recycle e-waste and the other connecting manufacturers who buy e-waste for remanufacturing, focusing on recycling electronic products such as mobile phones, computers, and digital products. Different from the traditional collection and distribution recycling method, manufacturers in the "Internet +" recycling platform do not directly provide services to consumers, but trade with consumers through the platform. Therefore, the market size of recycling platform enterprises is determined by both buyers and sellers. This new way of resource recycling and utilization uses the Internet to form the "Internet $+"$ recycling mode of online waste and offline logistics, which is helpful for solving the problems of the information asymmetry and low efficiency of centralized and distributed recycling in the traditional recycling mode. However, since the "Internet + " recycling platform is faced with two distinct types of user at the same time, there are many differences in the user scale of each type of user, which are in different market structures, further complicating the pricing problem of the platform.

Following up and observing some existing "Internet +" recycling platforms, we find that (1) e-waste products are very popular in the recycling and trading market. According to The Research Report on China's Online Second-hand Idle Commodity Trading Market in the First Quarter of 2019 released by BigData-Research, in the first quarter of 2019, the trading scale of China's second-hand idle commodity market reached 202.54 billion yuan, a year-on-year growth of $32.69 \%$. The report shows that the second-hand and unused goods that users often trade online are electronic and digital products, followed by mobile phones, household necessities, and video and audio appliances. (2) Under different market structures, when users choose the "Internet + " recycling platform, a reasonable selling/recycling price is the preferred factor. Platform reputation and subsidies are also important factors for users to consider. The Aihuishou platform was established in 2011, when the Internet trading and recycling platform was nascent, and Aihuishou was in the position of a monopoly platform. With the rapid development of similar platforms in recent years, a competing market structure gradually formed. However, since its birth, Aihuishou has always adopted a single price difference acquisition mode, which makes the platform excessively pursue high price differences and make use of opaque information to lower the recycling price and make profits. Due to its failure to repair and perfect its pricing strategy, the company's reputation has been damaged, leading to the loss of some users. This is the pricing and profit dilemma that this kind of recycling platform can easily fall into. According to the statistics, Dafeng recycling, which upgrades and innovates its pricing strategy and provides subsidies to users, gives registered users 15-60 RMB of economic value in recycling subsidies each time they use the platform. This strategy has attracted a large number of new users and increased customer loyalty.

Based on the above realities and two observations, a reasonable pricing mechanism is conducive to the improvement of the overall operation of the platform, so it is necessary to conduct in-depth research on the pricing strategies of such platforms. This paper uses the two-sided market theory, constructing a theoretical model in which different market structures and different ownership structures of consumers and manufacturers are studied. At the same time, this paper combines the industry characteristics of the platform, focusing on electronic waste recycling, considering the influence of inter-group network externalities (particularly membership externalities in this paper), matching efficiency, and the differentiation of recycling services. Finally, the pricing structure and profit of the platform and closed-loop supply chain are obtained. This paper aims to answer the following questions: (1) How do the various influencing factors introduced into the model affect the pricing and profitability of the platform? (2) What impact does the introduction of a platform recycling channel have on the pricing and profit of the closed-loop supply chain? (3) Under different market structures, how can the platform attract two-sided users, enhance competitiveness, and maintain sustainable development?

This paper uses two-sided market theory to analyze the pricing problem of electronics recycling platforms; in addition, the problem of two-sided markets is introduced to a closed-loop supply chain model, and the actual problem is abstracted to theory research. The remainder of this paper is organized as follows. Section 2 gives a literature review of theoretical and empirical research related to sustainable 
development and closed-loop supply chain management and two-sided market. Section 3 consists of the problem description and assumptions. At the same time, in Section 4, the pricing and profit of a closed-loop supply chain are analyzed using a Stackelberg game, making the paper both theoretical and practical. This paper first gives the optimal pricing decision of a monopolistic platform, then extends it to the pricing problem of a duopolistic competing platform and carries out a sensitivity analysis and comparative study. Section 5 presents the numerical simulation and numerical analysis to show the application of the model. Finally, conclusions are given in the Section 6.

\section{Literature Review}

The literature review in this paper mainly focuses on the theoretical research on two-sided markets, closed-loop supply chain pricing and electronic waste recycling.

The research on electronic waste recycling from the perspective of a two-sided market has important implications for electronic products that require special attention during recycling. At present, the research on the two-sided market theory mainly includes consumer behavior, platform behavior, and market behavior research. In respect to consumer behavior research, Hagiu [3] proposed that differences in user preferences regarding product diversity will coordinate with demand and significantly impact two-sided market pricing; the author adopted a three-stage game to analyze the question of how income on both sides shares a platform, indicating that the product developer, product diversity of market power, and user preferences will have important influences on platform pricing. Caillaud and Jullien [4] studied a kind of market creation two-sided market, focusing on the actual benefits and expenses obtained by two-sided users in the transaction, regardless of the number of users on the other side, and proposed a common phenomenon in the two-sided market: corresponding user subsidies would be made for competing platforms for user scale. In respect to platform behavior, Armstrong [5] proposed that the two-sided market includes the platform and users on both sides, and the platform connects the two sides like an intermediary. The revenue of one side is related to the number of users on the other side. Rochet and Tirole [6] investigated the pricing problem of monopolistic platforms and, by using externalities, studied the impact of price elasticity on the demands of users relating to the pricing of two-sided markets. They stated that platform enterprises should set lower prices for users with greater price elasticity of demand, while specifying higher prices for users with less price elasticity of demand. In respect to market behavior research, Zhang and Dong [7] analyzed the impact of maintaining the service differentiation of different operating costs on users' entry price, market share, and platform profit; studied the management of users with different operating costs on two-sided platforms; and provided a theoretical basis for enterprise management. However, in the current literatures on two-sided market theory, there are few papers focusing on the recycling of waste products, let alone researches on the recycling of electronic waste. In this paper, the two-sided market theory is applied to electronic waste recycling and to solving the pricing and maximum profit of "Internet +" recycling platforms. Management suggestions are provided for these typical two-sided platforms focusing on e-waste recycling.

The closed-loop supply chain, which follows the theory of circular economy and aims to maximize the product life cycle, is one of the effective ways to develop the remanufacturing industry. In recent years, there have been quite a few researches around the world devoted to the study of the closed-loop supply chain. Savaskan et al. [8] studied the selection of recycling channels and product pricing in the supply chain composed of manufacturers, retailers, and third parties as recyclers. Zhao et al. [9] studied manufacturers' remanufacturing and manufacturers' authorization to retailers under remanufacturing technology and analyzed the pricing, service, recycling decisions, and profit patterns of different remanufacturing supply chain members. Li et al. [10] established a two-phase model in which a monopolistic original equipment manufacturer provided a trade-in scheme to improve sales and collect used products, and used dynamic pricing to conduct decision research. Kabul et al. [11] considered a decentralized supply chain, consisting of a retailer and a supplier that provide services to forward-looking consumers over a two-year period, and addressed pricing and volume commitment 
issues from the perspective of both the retailer and supplier. Li et al. [12], taking into account consumers' preference for "replacing old products with new ones," constructed a profit model of manufacturers' hierarchical pricing and optimized it in different stages, obtained the optimal hierarchical pricing decision under subsidies, and gave practical suggestions to enterprises and governments. Zhu et al. [13] considered and paid attention to the impact of consumer behavior on the recycling process of waste electrical appliances and constructed a two-channel closed-loop supply chain model composed of retailers, manufacturers, and recycling platforms. The above researches mainly focus on recycling channel competition and coordination, manufacturers' monopoly decision, and consumers' channel preference, while few focus on the emerging recycling platforms. Moreover, the reality of electronic waste recycling needs further study. We focus on the reverse channel of the closed-loop supply chain and consider the recycling platform as a third party as a subject of the closed-loop supply chain. Then, Stackelberg game is used to study the pricing and profitability of the subjects in the supply chain in the following parts.

Electronic waste is not only a kind of pollutant, but also contains components with high recycling value. Therefore, how to regulate the recycling and disposal of these electronic wastes has become a matter of great concern in various countries. The Europe 2020 strategy has identified green development as a basic pillar of the EU's economic policy. On 2 March 2019, the regulation on the management of waste electrical and electronic products recycling in China was amended, marking a more standardized process of the Chinese government's recycling of waste electronic products. Awasthi et al. [14] are concerned that both India and China produce large amounts of e-waste, but both countries still have entrenched informal e-waste disposal sectors. They also argue that consumers need to be better informed about the dangers of e-waste pollution and to limit illegal cross-border electronic movement. Islam and Huda [15] propose that a large proportion of e-waste from other categories except television, computer, IT peripheral products, and mobile phones is still unregulated. They also conclude that Australia would produce 342 million t of e-waste in 2020 and is predicted to grow to $461 \mathrm{kt}$ in 2030 with an annual increase rate of around 3.7\% from 16 unregulated types of electrical and electronic equipment. Gao et al. [16] suggest optimizing the e-waste recycling system in terms of subsidies, recycling subjects, and policies. Four kinds of e-waste recycling and disposal models under government subsidy were constructed by Stackelberg game theory. The relative decision and profit function of each subject in the four models are compared and analyzed. Taking into account the government reward and punishment mechanism and the cost-profit-sharing contract of a closed-loop supply chain, Wang W.B. et al. [17] study how the retail price, repurchase price, and recycling rate of discarded electronic products and the profit of a closed-loop supply chain change, and provide some theoretical basis for the recycling of electronic waste. Wang X.V. et al. [18] provide an integrated and reliable cyber-avatar of the individual Waste Electrical and Electronic Equipment (WEEE) and propose a new digital dual system based on waste electrical and electronic equipment recycling to support manufacturing/remanufacturing operations throughout the product life cycle from design to recycling. Although there are many literatures on e-waste and e-waste recycling, the research related to the emerging "Internet +" platforms needs to be further developed. In response to the call of the state and the trend of the times, this paper selects the emerging "Internet +" platforms as the main subjects of recycling, and provides pricing decisions and management implications for the recycling and disposal of electronic waste of these platforms.

To sum up, the two-sided market has become an important strategy for the operation and profit of platform enterprises and has produced many results in model construction and empirical research. However, there is still a lack of relevant research on the recycling of electronic waste, and the topic of "Internet + recycling" platform enterprises needs to be further explored. Therefore, in this paper, on the basis of the existing literature and in order to reduce the information asymmetry between manufacturers and consumers and lower the search costs when the two look for each other, a two-sided market linking consumers and manufacturers for e-waste recycling is established. As recycling platform enterprises often have network characteristics, their investment costs and technical requirements are 
high, and the market size is large, so they often occupy the majority of the market share, showing a "dominance" or "several dominators" situation. In order to reflect the reality of recycling platform enterprises in a more comprehensive way, this paper considers the pricing strategies of such enterprises under different market structures, and studies the scale of consumers and manufacturers, platform pricing, and maximum profit from monopolized markets and competing markets.

The research in this paper differs from previous studies in the following three aspects: (1) this paper provides an innovative perspective for e-waste recycling, namely the two-sided market theory, and provides decision-making suggestions for e-waste recycling and disposal. (2) This paper focuses on the emerging "Internet + " recycling platforms and studies the pricing and profitability of such platforms in the process of recycling e-waste through sensitivity analysis of various factors. (3) Stackelberg game is used to study the optimal pricing strategy and influencing factors of e-waste supply chains led by manufacturers, and the decision-making and influencing factors of e-waste supply chains under different market structures are discussed. A brief summary of the literature review is shown in Table 1.

Table 1. A brief summary of the literature review.

\begin{tabular}{|c|c|c|}
\hline Research Field & Author(s) & Main Points \\
\hline \multirow{5}{*}{ Two-sided market } & Hagiu, A. & $\begin{array}{l}\text { Differences in user preferences regarding product diversity will coordinate with } \\
\text { demand and significantly impact two-sided market pricing }\end{array}$ \\
\hline & Caillaud, B., Jullien, B. & $\begin{array}{l}\text { Propose a common phenomenon in the two-sided market: corresponding user } \\
\text { subsidies would be made for competing platforms for user scale }\end{array}$ \\
\hline & Armstrong, $\mathrm{M}$. & The revenue of one side is related to the number of users on the other side \\
\hline & Rochet, J.C., Tirole, J. & $\begin{array}{l}\text { Platform enterprises should set lower prices for users with greater price elasticity of } \\
\text { demand, while specifying higher prices for users with less price elasticity of demand. } \\
\text { In respect to market behavior research }\end{array}$ \\
\hline & Zhang, K., Dong, Y.S. & Study the management of users with different operating costs on two-sided platforms \\
\hline \multicolumn{3}{|c|}{$\begin{array}{l}\text { However, in the current literatures on two-sided market theory, there are few papers focusing on the recycling of waste products, let alone } \\
\text { researches on the recycling of electronic waste. In this paper, the two-sided market theory is applied to electronic waste recycling and to } \\
\text { solving the pricing and maximum profit of "Internet }+ \text { " recycling platforms. Management suggestions are provided for these typical } \\
\text { two-sided platforms focusing on e-waste recycling. }\end{array}$} \\
\hline \multirow{6}{*}{$\begin{array}{l}\text { Closed-loop supply } \\
\text { chain pricing }\end{array}$} & $\begin{array}{l}\text { Savaskan, R.C., } \\
\text { Bhattacharya, S., van } \\
\text { Wassenhove, L.N. }\end{array}$ & $\begin{array}{l}\text { Study the selection of recycling channels and product pricing in the supply chain } \\
\text { composed of manufacturers, retailers, and third parties as recyclers }\end{array}$ \\
\hline & Zhao, J., Wang, C., Xu, L. & $\begin{array}{l}\text { Study manufacturers' remanufacturing and manufacturers' authorization to retailers } \\
\text { under remanufacturing technology and analyze the pricing, service, recycling } \\
\text { decisions, and profit patterns of different remanufacturing supply chain members }\end{array}$ \\
\hline & $\begin{array}{l}\text { Li, Y., Feng, L., } \\
\text { Govindan, K., et al. }\end{array}$ & $\begin{array}{l}\text { Establish a two-phase model in which a monopolistic original equipment } \\
\text { manufacturer provides a trade-in scheme to improve sales and collects used products, } \\
\text { and use dynamic pricing to conduct decision research }\end{array}$ \\
\hline & $\begin{array}{l}\text { Kabul, M.O., } \\
\text { Parlakturk, A.K. }\end{array}$ & $\begin{array}{l}\text { Consider a decentralized supply chain and address pricing and volume commitment } \\
\text { issues from the perspective of both the retailer and supplier }\end{array}$ \\
\hline & $\begin{array}{l}\text { Yan, L., Xinyi, L., } \\
\text { Qingli, D. }\end{array}$ & $\begin{array}{l}\text { Taking into account consumers' preference for "replacing old products with new ones," } \\
\text { construct a profit model of manufacturers' hierarchical pricing and optimize it in } \\
\text { different stages, obtain the optimal hierarchical pricing decision under subsidies }\end{array}$ \\
\hline & Zhu, X., Wang, J., Tang, J. & $\begin{array}{l}\text { Consider the impact of consumer behavior on the recycling process of waste electrical } \\
\text { appliances and construct a two-channel closed-loop supply chain model }\end{array}$ \\
\hline \multicolumn{3}{|c|}{$\begin{array}{l}\text { The above researches mainly focus on recycling channel competition and coordination, manufacturers' monopoly decision and consumers' } \\
\text { channel preference, while few focus on the emerging recycling platforms. Moreover, the reality of electronic waste recycling needs further } \\
\text { study. We focus on the reverse channel of the closed-loop supply chain and consider the recycling platform as a third party as a subject of } \\
\text { the closed-loop supply chain. Then Stackelberg game is used to study the pricing and profitability of the subjects in the supply chain. }\end{array}$} \\
\hline
\end{tabular}


Table 1. Cont.

\begin{tabular}{|c|c|c|}
\hline Research Field & Author(s) & Main Points \\
\hline \multirow{5}{*}{$\begin{array}{l}\text { Electronic waste } \\
\text { recycling }\end{array}$} & Awasthi, A.K., Li, J. & $\begin{array}{l}\text { Propose to better educate consumers on the dangers of e-waste contamination and } \\
\text { restrict the illegal movement of e-waste across borders, and support the development } \\
\text { of a formal, regulated e-waste processing industry }\end{array}$ \\
\hline & Md Islam, T., Huda, N. & $\begin{array}{c}\text { Australia would produce } 342 \text { million t of e-waste in } 2020 \text { and is predicted to grow to } \\
461 \mathrm{kt} \text { in } 2030 \text { with an annual increase rate of around } 3.7 \% \text { from the } 16 \text { types of } \\
\text { unregulated electrical and electronic equipment }\end{array}$ \\
\hline & Gao, M., Liao, M.L. & $\begin{array}{l}\text { Four kinds of e-waste recycling and disposal models under government subsidy were } \\
\text { constructed using Stackelberg game theory }\end{array}$ \\
\hline & $\begin{array}{l}\text { Wang, W.B., Ding, J.F., } \\
\text { Da, Q.L. }\end{array}$ & $\begin{array}{l}\text { Study how the retail price, repurchase price, and recycling rate of discarded electronic } \\
\text { products and the profits of closed-loop supply chain change }\end{array}$ \\
\hline & Wang, X.V., Wang, L. & $\begin{array}{l}\text { Provide an integrated and reliable cyber-avatar of the individual WEEE and propose a } \\
\text { new digital dual system based on waste electrical and electronic equipment recycling. }\end{array}$ \\
\hline
\end{tabular}

\section{Problem Description and Hypotheses}

\subsection{Problem Description}

In the service process of a recycling platform, three main subjects are involved: manufacturers, consumers, and platforms. A recycling platform connects consumers and manufacturers on both sides, which together constitute the two-sided market for recycling platform operation. When consumers need to recycle electronic waste, they submit relevant information to the platform through online websites or offline recycling stores, and the platform will match corresponding manufacturers according to the type of electronic waste product, remanufacturability, and parts, and other information submitted by consumers.

According to the industry characteristics of "Internet + " recycling platform enterprises, this paper considers the influence of inter-group network externalities, matching efficiency and service differentiation on platform pricing strategies. $\theta_{s}$ represents the utility added to the consumer for each additional manufacturer, while $\theta_{b}$ represents the utility added to the manufacturer for each additional consumer. $n_{b}$ is the actual number of buyers who join the platform when sellers join a platform at the same time. $n_{s}$ is the actual number of sellers who join the platform when buyers join a platform at the same time. When more consumers choose a platform to recycle electronic waste, the remanufacturing opportunities that manufacturers receive through the platform will increase, and as more and more manufacturers join the platform, competition pressure increases and the service quality will be improved, so as to attract more users to the recycle trading platform. This is the manifestation of cross-network externalities at work. For recycling platform enterprises, the matching efficiency $\varphi$ between manufacturers and consumers is also worth discussing. A platform with high matching efficiency will stand out from the competition, consumers and manufacturers will enjoy better services, and their loyalty to the platform will also increase. The set matching efficiency for consumers and manufacturers in a two-sided market scale takes a linear function, $\delta_{b}, \delta_{s}$ for compatibility, $\hat{\varphi}_{b}, \hat{\varphi}_{s}$ for said consumers' and manufacturers' minimum waiting time, respectively (namely platform matching efficiency), and $\omega_{b}, \omega_{s}$ for consumers and manufacturers sensitive coefficient of waiting time. Hence, the matching efficiency function is:

$$
\varphi_{b}=\hat{\varphi}_{b}+\omega_{b} n_{s}, \quad \varphi_{s}=\hat{\varphi}_{s}+\omega_{s} n_{b}
$$

At the same time, this paper also considers the single manufacturer loyalty income factor, because a manufacturer considering factors such as commissions and operating costs often chooses single access, characterized by manufacturers' single ownership. For such manufacturers with high trading frequency and good feedback, a platform will offer a certain subsidy; $h$ is loyal revenue. In addition, in 
order to reflect the realistic background more comprehensively, this paper considers the opportunity cost factor in the monopoly platform. $\mu$ represents that consumers do not use the opportunity cost of a platform, $x$ represents the ease of consumers using other ways to find manufacturers, and it obeys uniform distribution from 0 to $1 . \gamma$ represents the opportunity cost of the manufacturer without the help of platforms, and $y$ represents the difficulty for the manufacturer to find consumers by other means, subjecting it to the uniform distribution from 0 to 1 .

In addition, this paper introduces the two-sided market's actual problem to the closed-loop supply chain model. A closed-loop supply chain model is constructed by manufacturers, the third-party collection platform, and the user group. Because the paper considers the pricing of the recycling platform market under stable conditions, at the beginning of the development platform, through various forms of subsidy, consumers and manufacturers can be persuaded to join, but consumers and manufacturers still need to pay the service fee to the platform. The game order is as follows: first, the third-party platform pays $P_{c}$ to collect electronic waste from consumers. As consumers join the platform, the third-party platform charges consumers $P_{s}$. Manufacturers set the recycling price $b$ and buy electronic waste from the platform for recycling and remanufacturing production; due to manufacturers joining the trading platform, the third-party platform charges manufacturers $P_{b}$. According to the production cost price, manufacturers set the price $p$ to sell new products to the market. Operation flow chart of a recycling platform is shown in Figure 1.

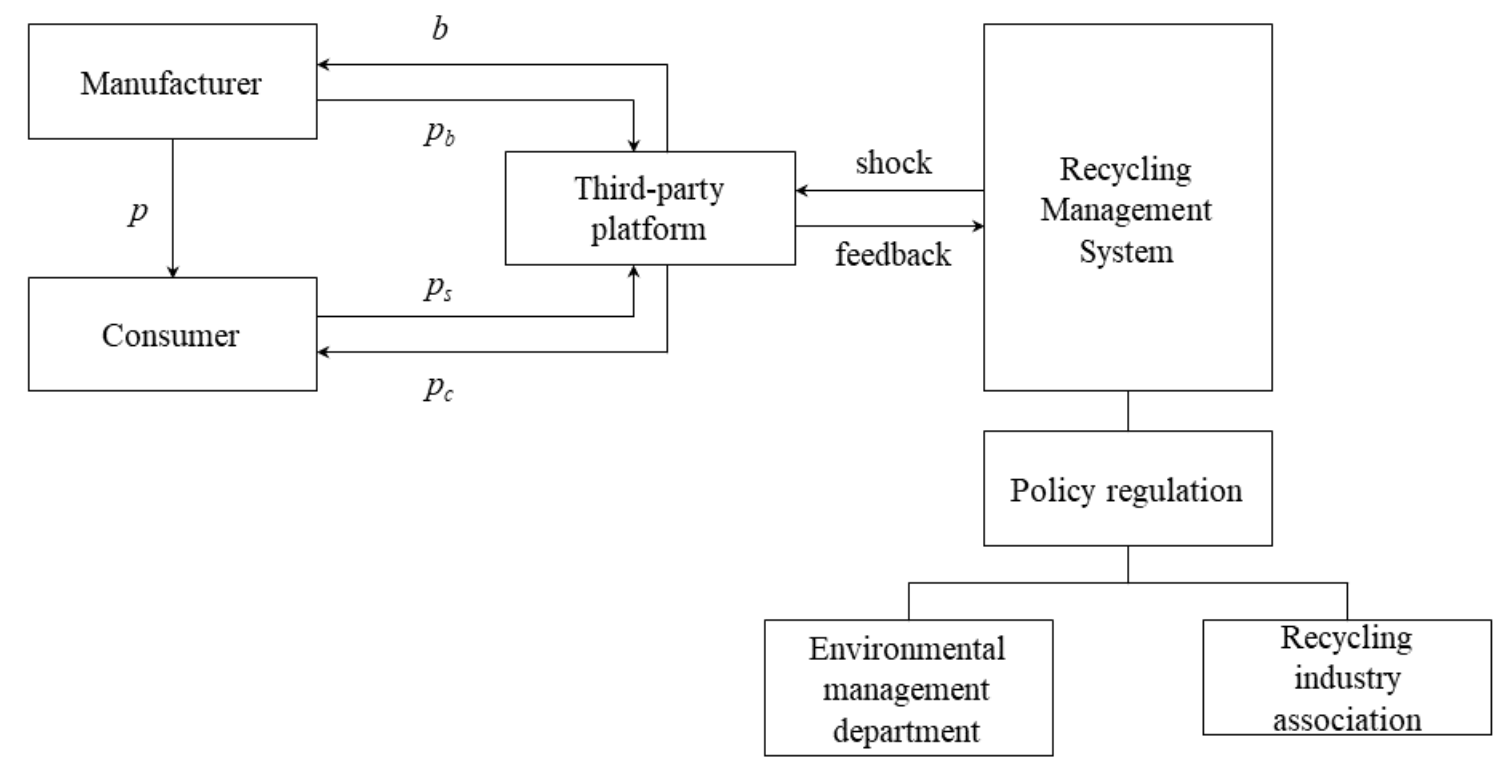

Figure 1. Operation flow chart of a recycling platform.

Since recycling platforms are under the jurisdiction of command of recycling management system, which is restricted by policy supervision, this paper selects environmental management departments and recycling industry associations to represent policy regulations on recycling platforms from the perspective of the government and society, respectively. Moreover, a recycling management system is regulated by policies, and the corresponding policy regulations are put forward for the recycling platforms it manages. In turn, the achievements made by the recycling platforms in recycling also have a feedback effect on the whole recycling management system, which may be positive or negative.

\subsection{Assumptions}

Hypothesis 1 (H1). $P_{b}+P_{s}+b>P_{c}$ to ensure the profit of each subject. $C_{m}$ is the unit cost of the new product, and $C_{r}$ is the unit cost of the remanufactured product. There must be $C_{r}<C_{m}$; the difference $\Delta=C_{m}-C_{r}$ represents the cost savings of remanufacturing. 
Hypothesis 2 (H2). All e-waste recycled by the third-party platform goes to the manufacturer, who is responsible for remanufacturing. Moreover, consumers have the same purchase intention for new products and remanufactured products on the market, and both products have the same market price.

Hypothesis 3 (H3). Both manufacturers and consumers are rational, and only when the utility is greater than 0 will they join the platform to trade.

Hypothesis 4 (H4). According to the research of Savaskan et al. [8], it is assumed that the demand function of the market for remanufactured products is $q=\alpha-\beta p, \alpha, \beta>0$ and all are constant.

Hypothesis 5 (H5). Let the recycling function of waste products be $G\left(P_{c}\right)=m+\rho P_{c}, m, \rho>0$, and all are constant. $\rho$ is the sensitivity and $m$ is the quantity of waste products voluntarily recycled by consumers when there is no recycling subsidy; that is, consumers' willingness to recycle.

Note: the subscript " $\mathrm{m}$ " and " $\mathrm{r}$ " represent the manufacturer and the recycling platform, respectively.

\section{Model Construction and Solution}

\subsection{Pricing of Monopoly Platforms}

For manufacturers, there are two main ways to make a profit: first, by selling remanufactured products, and second, by recycling products. Thus, the profit function of the manufacturer can be obtained:

$$
\pi_{m}(b, p)=\left(p-C_{m}\right) q+\left(C_{m}-C_{r}-b\right) G\left(P_{c}\right)-P_{b}
$$

According to the previous description, the utility functions of manufacturers and consumers in the monopoly platform are:

$$
\left\{\begin{array}{l}
U_{s}=\theta_{s} n_{b}-P_{s}+\delta_{s} \varphi_{s}-\mu x \\
U_{b}=\theta_{b} n_{s}-P_{b}+\delta_{b} \varphi_{b}-\gamma y
\end{array}\right.
$$

Therefore, the scale of consumers and manufacturers is expressed in probability as:

$$
\left\{\begin{array}{l}
n_{s}=\frac{\theta_{s} n_{b}-P_{s}+\delta_{s}\left(\hat{\varphi}_{s}+\omega_{s} n_{b}\right)}{\mu} \\
n_{b}=\frac{\theta_{b} n_{s}-P_{b}+\delta_{b}\left(\hat{\varphi}_{b}+\omega_{b} n_{s}\right)}{\gamma}
\end{array}\right.
$$

Simultaneous equations are obtained:

$$
\left\{\begin{array}{l}
n_{s}=\frac{-\Upsilon P_{s}+\delta_{b} \theta_{s} \hat{\varphi}_{b}+\Upsilon \delta_{s} \hat{\varphi}_{s}+\delta_{b} \delta_{s} \hat{\varphi}_{b} \omega_{s}-P_{b}\left(\theta_{s}+\delta_{s} \omega_{s}\right)}{\mu \Upsilon-\theta_{b}\left(\theta_{s}+\delta_{s} \omega_{s}\right)-\delta_{b} \omega_{b}\left(\theta_{s}+\delta_{s} \omega_{s}\right)} \\
n_{b}=\frac{-\mu P_{b}+\mu \delta_{b} \hat{\varphi}_{b}+\delta_{s} \theta_{b} \hat{\varphi}_{s}+\delta_{b} \delta_{s} \hat{\varphi}_{s} \omega_{b}-P_{s}\left(\theta_{b}+\delta_{b} \omega_{b}\right)}{\mu \Upsilon-\theta_{b}\left(\theta_{s}+\delta_{s} \omega_{s}\right)-\delta_{b} \omega_{b}\left(\theta_{s}+\delta_{s} \omega_{s}\right)}
\end{array}\right.
$$

Here, we refer to the previous literature related to two-sided market pricing $[6,19,20]$ and express the number of consumers and manufacturers in the form of probability, which is conducive to the simplicity of the formula. The actual quantity is equal to the corresponding probability times the quantity base, which will not affect the subsequent algorithm and conclusion.

In this paper, the transaction times $[6,19]$ are set in the form of the Cobb-Douglas demand function, and the profit function of the platform can be further obtained as

$$
\pi_{r}\left(P_{b}, P_{s}\right)=P_{s} t_{s} n_{s}+\tau P_{b} t_{b} n_{b}+\left(b-P_{c}\right) G\left(P_{c}\right)
$$


The inverse induction method was used to solve the model, and Equation (5) was substituted into Equation (6). Firstly, the derivatives of $\pi_{r}$ with respect to $P_{b}, P_{s}$ and $P_{c}$ were respectively obtained. Then, the optimal price of service charge on both sides of the solution platform was set as follows:

$$
\begin{gathered}
P_{b}^{*}=\frac{t_{s}\left(t_{s}\left(\theta_{s}+\delta_{s} \omega_{s}\right)\left(\Upsilon \delta_{s} \hat{\varphi}_{s}+\delta_{b} \hat{\varphi}_{b}\left(\theta_{s}+\delta_{s} \omega_{s}\right)\right)+t_{b}\left(-\Upsilon \delta_{s} \hat{\varphi}_{s}+\delta_{b}^{2} \hat{\varphi}_{b} \omega_{b}\left(\theta_{s}+\delta_{s} \omega_{s}\right)+\delta_{b}\left(-\Upsilon \delta_{s} \hat{\varphi}_{s} \omega_{b}+\varphi_{b}\left(-2 \mu \Upsilon+\theta_{b}\left(\theta_{s}+\delta_{s} \omega_{s}\right)\right)\right)\right)\right.}{t_{b}^{2}\left(\theta_{b}+\delta_{b} \omega_{b}\right)^{2}+t_{s}^{2}\left(\theta_{s}+\delta_{s} \omega_{s}\right)^{2}+2 t_{b} t_{s}\left(-2 \mu \Upsilon+\theta_{b}\left(\theta_{s}+\delta_{s} \omega_{s}\right)+\delta_{b} \omega_{b}\left(\theta_{s}+\delta_{s} \omega_{s}\right)\right)} \\
P_{s}^{*}=\frac{t_{b}\left(t_{b}\left(\theta_{b}+\delta_{b} \omega_{b}\right)\left(\delta_{s} \theta_{b} \hat{\varphi}_{s}+\delta_{b}\left(\mu \hat{\varphi}_{b}+\delta_{s} \hat{\varphi}_{s} \omega_{b}\right)\right)+t_{s}\left(\delta_{b}\left(3 \mu \hat{\varphi}_{b}+\delta_{s} \hat{\varphi}_{s} \omega_{b}\right)\left(\theta_{s}+\delta_{s} \omega_{s}\right)+\delta_{s} \hat{\varphi}_{s}\left(2 \mu \Upsilon+\theta_{b}\left(\theta_{s}+\delta_{s} \omega_{s}\right)\right)\right)\right)}{t_{b}^{2}\left(\theta_{b}+\delta_{b} \omega_{b}\right)^{2}+t_{s}^{2}\left(\theta_{s}+\delta_{s} \omega_{s}\right)^{2}+2 t_{b} t_{s}\left(-2 \mu \Upsilon+\theta_{b}\left(\theta_{s}+\delta_{s} \omega_{s}\right)+\delta_{b} \omega_{b}\left(\theta_{s}+\delta_{s} \omega_{s}\right)\right)} \\
P_{c}^{*}=\frac{3 m-\rho C_{m}+\rho C_{r}}{4 \rho}
\end{gathered}
$$

Derive $\pi_{m}$ with respect to $p$ and $b$, then make all equations equal to 0 , simultaneous equations to $p^{*}=\frac{\alpha+\beta C_{m}}{2 \beta}, b^{*}=\frac{-m+\rho C_{m}-\rho C_{r}}{2 \rho}$.

Plug $p^{*}, b^{*}, P_{c}^{*}, P_{b^{\prime}}^{*}$, and $P_{s}^{*}$ into Equations (2) and (6), then the optimal profit of the manufacturer and the platform is $\pi_{m}^{*}, \pi_{r}^{*}$; the two together can get the optimal profit of the closed-loop supply chain system $\pi^{*}$.

Proposition 1. $P_{s}^{*}, P_{b}^{*}$ decrease with the increase of $\theta_{s}$ in the case of constant $\theta_{b}, P_{s}^{*}, P_{b}^{*}$ decrease with the increase of $\theta_{b}$ in the case of constant $\theta_{s}$.

Proposition 1 shows that the prices the platform charges consumers and manufacturers are negatively related to the intensity of inter-group network externalities; that is, when the inter-group network externalities strengthen gradually, the price charged by the platform to two-sided users will then decline, and when the inter-group network externality strength increases to a certain extent, the pricing of one or both of the platforms may be zero or negative. When negative pricing happens, the platform also provides recycling subsidies for the two-sided users; this situation is often more common in a start-up platform for enterprise management.

Proposition 2. As $m$ increases, $P_{c}^{*}$ increases and $b^{*}$ decreases.

Proposition 2 shows that (1) with the increase in consumers' willingness to recycle, the recycling transfer price given by the platform to consumers will increase accordingly. This is a common recycling subsidy measure given by a platform to consumers, which is conducive to encouraging consumers to recycle actively and increases the customer stickiness of the platform. (2) With the increase in consumers' willingness to recycle, the recycling transfer price offered by manufacturers to the platform will decrease. This is because the increase in consumers' willingness to recycle will directly lead to an increase in the quantity of recycled products. When the scale of manufacturers remains unchanged, the recycling transfer price they are willing to provide will decrease.

Proposition 3. As the prices of $\omega_{b}$ and $\omega_{s}$ increase, both $P_{s}^{*}$ and $P_{b}^{*}$ are reduced by the price that the monopoly platform charges both consumers and manufacturers.

Proposition 3 shows that when the time sensitivity of consumers and manufacturers to waiting matches increases, the pricing of both sides of the platform will decrease. Discussed here are two kinds of market conditions: (1) When the platform for enterprises is in the start-up stage, the platform for two-sided users often undertakes a follow-up tracking feedback survey; when it is found that two-sided users are more sensitive to waiting time, the platform tends to adopt a mass reduction method to attract new customers to maintain enterprise users on the early scale, so the platform in this phase tends to have negative profits. (2) When the platform enterprise is in the stage of stable development, the platform has undergone sufficient technical upgrading and received favorable user feedback. Even when the platform receives negative feedback from individual two-sided users on the 
matching time, the platform compensates the users by reducing prices and subsidizing, but the overall profit of the platform still shows an upward trend.

\subsection{Pricing of Competing Platforms}

In the actual operation process of recycling platforms, users' loyalty is relatively low, which is often manifested as multi-homing, while manufacturers often express it as single-homing, considering registration fees and operating costs. This paper assumes that the two competing recycling platforms $(i, j)$ are located at the ends of a linear city, and the length of the linear city is 1 . The distribution of users and manufacturers in linear cities is shown in Figure 2. Among them, the scale of single-homing consumers of the platform $i, j$ are, respectively, $n_{s}^{i}, n_{s}^{j}$. The inter-group section $x_{2}-x_{1}$ is the scale of multi-homing consumers and the scale of single-homing consumers of the platform $i, j$ is, respectively, $n_{b}^{i}, n_{b}^{j} . T_{b}, T_{s}$ are the service differentiation provided by the platform to manufacturers and consumers. The utility functions of the user and manufacturer can be obtained as shown in Equation (10):

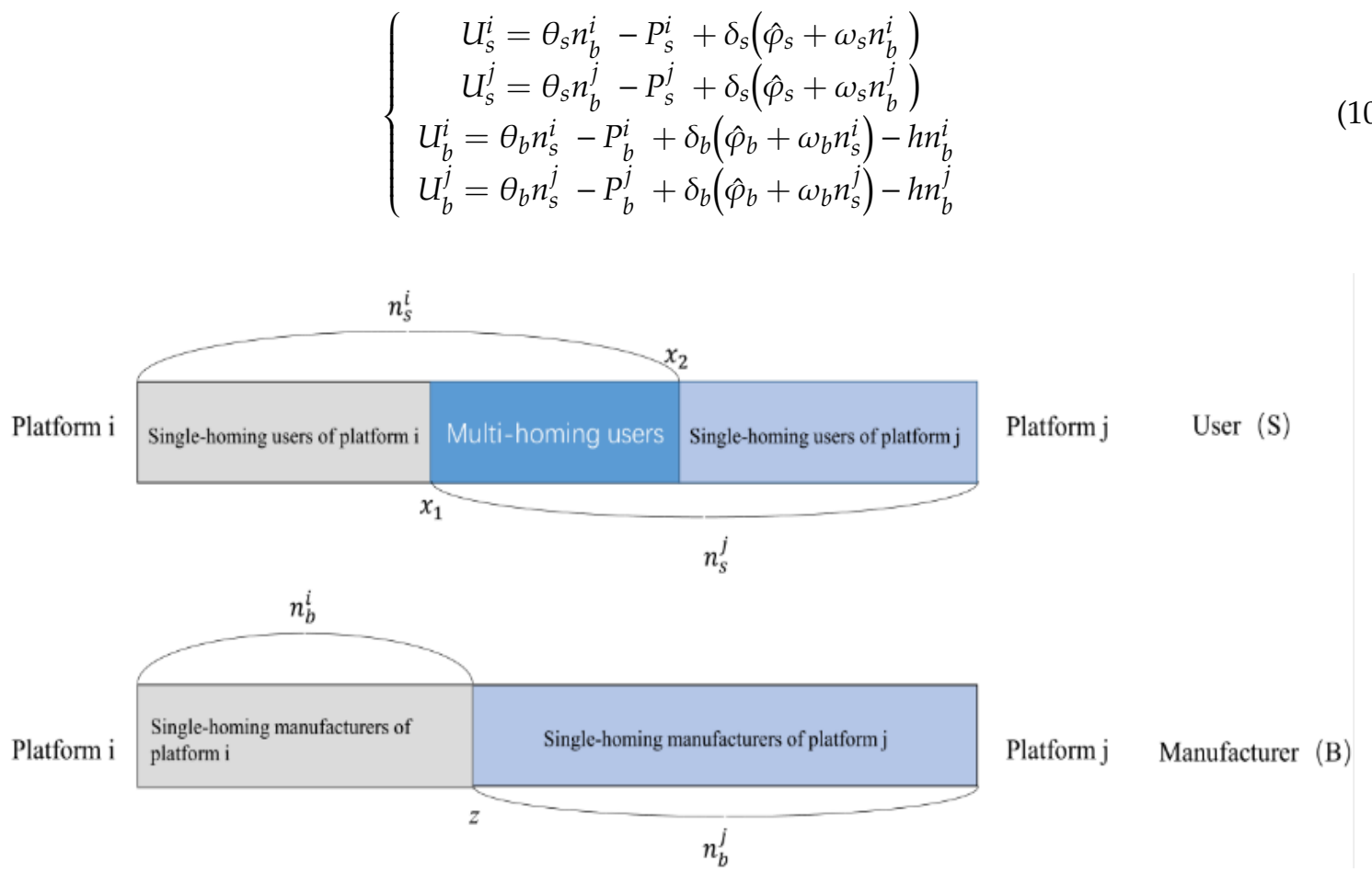

Figure 2. Pricing model with multi-homing consumers and single-homing manufacturers.

The Hotelling model shown in Figure 2 supposes that the distance of a consumer from platform $\mathrm{i}$ is $x_{1}$, and another consumer's distance from platform $\mathrm{i}$ is $x_{2}$. At $x_{1}$, the net profits of single-homing consumers in platform $i$ and multi-homing consumers are the same. At $x_{2}$, the net profits of single-homing consumers in platform $j$ and multi-homing consumers are the same. Thus, the following equations can be obtained:

$$
\begin{gathered}
\theta_{s} n_{b}^{j}-P_{s}^{j}+\delta_{s}\left(\hat{\varphi}_{s}+\delta_{s} n_{b}^{j}\right)-T_{s}\left(1-x_{2}\right)=\theta_{s}\left(n_{b}^{i}+n_{b}^{j}\right)-P_{s}^{i}-P_{s}^{j}+\delta_{s}\left(\hat{\varphi}_{s}+\delta_{s} n_{b}^{i}+\delta_{s} n_{b}^{j}\right)-T_{s} \\
\theta_{s} n_{b}^{i}-P_{s}^{i}+\delta_{s}\left(\hat{\varphi}_{s}+\delta_{s} n_{b}^{i}\right)-T_{s} x_{1}=\theta_{s}\left(n_{b}^{i}+n_{b}^{j}\right)-P_{s}^{i}-P_{s}^{j}+\delta_{s}\left(\hat{\varphi}_{s}+\delta_{s} n_{b}^{i}+\delta_{s} n_{b}^{j}\right)-T_{s}
\end{gathered}
$$

Solve equations:

$$
x_{1}=\frac{P_{s}^{j}+T_{s}-n^{j}{ }_{b} \theta_{s}-n_{b}^{j} \delta_{s} \omega_{s}}{T_{s}}, x_{2}=\frac{-P_{s}^{i}+n^{i}{ }_{b} \theta_{s}+n^{i}{ }_{b} \delta_{s} \omega_{s}}{T_{s}}
$$


Since $n_{s}^{i}=x_{2}, n_{s}^{j}=1-x_{1}$, the user scale of platform $\mathrm{i}$ and platform $\mathrm{j}$ is:

$$
n_{s}^{i}=\frac{-P_{s}^{i}+n_{b}^{i}\left(\theta_{s}+\delta_{s} \omega_{s}\right)}{T_{s}}, n_{s}^{j}=\frac{-P^{j}{ }_{s}+n^{j}{ }_{b}\left(\theta_{s}+\delta_{s} \omega_{s}\right)}{T_{s}}
$$

Then, the size of the manufacturer is obtained, and $\mathrm{z}$ is used to represent the location of the consumer in the linear city; subsequently, the manufacturer's difference can be obtained as follows:

$$
z=\frac{U_{b}^{i}-U_{b}^{j}+T_{b}}{2 T_{b}}=\frac{\theta_{b} n_{s}^{i}-P_{b}^{i}+\delta_{b}\left(\hat{\varphi}_{b}+\delta_{b} n_{s}^{i}\right)-\theta_{b} n_{s}^{j}+P_{b}^{j}-\delta_{b}\left(\hat{\varphi}_{b}+\delta_{b} n_{s}^{j}\right)+T_{b}-h n_{b}^{i}+h n_{b}^{j}}{2 T_{b}}
$$

By combining this with Equation (12), the sizes of multi-homing consumers and single-homing manufacturers can be obtained as follows:

$$
\begin{gathered}
n_{b}^{i}=\frac{\left(h-P_{b}^{i}+P_{b}^{j}+T_{b}\right) T_{s}-\left(\delta_{b}^{2}+\theta_{b}\right)\left(P_{s}^{i}-P_{s}^{j}+\theta_{s}+\delta_{s} \omega_{s}\right)}{2\left(\left(h+T_{b}\right) T_{s}-\left(\delta_{b}^{2}+\theta_{b}\right)\left(\theta_{s}+\delta_{s} \omega_{s}\right)\right)} \\
n_{b}^{j}=1+\frac{-\left(h-P_{b}^{i}+P_{b}^{j}+T_{b}\right) T_{s}+\left(\delta_{b}^{2}+\theta_{b}\right)\left(P_{s}^{i}-P_{s}^{j}+\theta_{s}+\delta_{s} \omega_{s}\right)}{2\left(\left(h+T_{b}\right) T_{s}-\left(\delta_{b}^{2}+\theta_{b}\right)\left(\theta_{s}+\delta_{s} \omega_{s}\right)\right)}
\end{gathered}
$$

At this point, the profit function of the recycling platform is as shown in Equation (16):

$$
\begin{aligned}
& \pi_{r}^{i}=P_{s}^{i} t_{s} n_{s}^{i}+\left(P_{b}^{i} t_{b}-h\right) n_{b}^{i}+\left(b_{i}-P_{c}^{i}\right) G\left(P_{c}^{i}\right) \\
& \pi_{r}^{j}=P_{s}^{j} t_{s} n_{s}^{j}+\left(P_{b}^{j} t_{b}-h\right) n_{b}^{j}+\left(b_{j}-P_{c}^{j}\right) G\left(P_{c}^{j}\right)
\end{aligned}
$$

The model is solved by using backward induction: type (15) into type (16). Based on the results of the study of the two-sided market's characteristics, this paper focuses on the symmetric equilibrium under the condition of the solution, assuming $P_{s}^{i}=P_{s}^{j}, P_{b}^{i}=P_{b}^{j}$. First, derive $\pi_{r}^{i}$ with respect to $P_{b}^{i}, P_{s}^{i}$ and $P_{c}^{i}$. Then, arrange the equations and solve them. Thus, the pricing structure of consumers and manufacturers is shown in Equations (17)-(19).

$$
\begin{gathered}
P_{s}^{i}=P_{s}^{j}=\frac{1}{4}\left(\theta_{b}-\theta_{s}+\delta_{b} \omega_{b}-\delta_{s} \omega_{s}\right) \\
P_{b}^{i}=P_{b}^{j}=\frac{T_{b} T_{s}-\theta_{b}+\theta_{s}+\delta_{b} \omega_{b}-\delta_{s} \omega_{s}-\left(\theta_{s}-\delta_{b} \omega_{b}\right)\left(\theta_{b}-\delta_{s} \omega_{s}\right)}{4 T_{s}} \\
P_{c}^{i}=P_{c}^{j}=\frac{-m+b \rho}{2 \rho}
\end{gathered}
$$

Proof. Because the problem has multiple feasible solutions, this paper focuses only on equilibrium under the condition of symmetric solutions. Thus, we assume that $P_{b}^{i}=P_{b}^{j}, P_{s}^{i}=P_{s}^{j}, P_{c}^{i}=P_{c}^{j}$, according to the equilibrium condition of the Hotelling model, combining type (13), (15) and (16) to derive $\pi_{r}^{i}$ with respect to $P_{b}^{i}, P_{s}^{i}$ and $P_{c}^{i}$ and arrange the equations. Thus, the pricing structure of consumers and manufacturers can be obtained.

Proposition 4. With the increase of $T_{b}, T_{s}, P_{s}^{i}, P_{s}^{j}$ remains unchanged while $P_{b}^{i}, P_{b}^{j}$ increases.

Proposition 4 indicates that the differentiation of service between platforms determines the pricing of two-sided users by platform and the ownership structure of two-sided users. Changes in the differentiation of service will only affect the pricing of the single-homing party, but not the multi-homing 
party. With the increase in the differentiation of service, the platform cost will inevitably increase the pricing of the single-homing manufacturer. Due to the low loyalty of multi-homing consumers, the change in the differentiation of service hardly affects them, but the increase in the differentiation of service will lead to an increase in the conversion cost, so multi-homing consumers must consider the issue of conversion cost. Therefore, a certain management implication can be obtained: enhancing the differentiation of service among platforms - that is, improving the competitiveness of products and services-is conducive to reducing the proportion of multi-homing users and enhancing user stickiness.

By substituting Equation (17) into Equations (13) and (15), the user size of manufacturers and consumers in the equilibrium state can be obtained, as follows:

$$
\begin{gathered}
n_{b}^{i}=n_{b}^{j}=1 / 2 \\
n_{s}^{i}=n_{s}^{j}=\frac{\theta_{s}+\delta_{s} \omega_{s}+\theta_{b}+\delta_{b} \omega_{b}}{4 T_{s}}
\end{gathered}
$$

Substituting Equations (17) and (20) into Equation (16), the optimal profit of the platform in the equilibrium state can be obtained, as follows:

$$
\begin{aligned}
& \pi_{r}^{i_{r}^{*}=\pi_{r}^{j^{*}}} \\
& =\frac{\left(2 m \beta+\alpha \rho+\beta \rho C_{m}\right)\left(m+\rho C_{m}-\rho C_{r}\right)}{8 \beta \rho} \\
& -\frac{t_{s}\left(\theta_{b}-\theta_{s}+\delta_{b} \omega_{b}-\delta_{s} \omega_{s}\right)\left(\theta_{b}+\theta_{s}+\delta_{b} \omega_{b}+\delta_{s} \omega_{s}\right)+2\left(4 h T_{s}-t_{b}\left(T_{b} T_{s}+\theta_{b}-\theta_{s}+\delta_{b} \omega_{b}-\delta_{s} \omega_{s}-\left(\theta_{s}-\delta_{b} \omega_{b}\right)\left(\theta_{b}-\delta_{s} \omega_{s}\right)\right)\right)}{16 T_{s}}
\end{aligned}
$$

For manufacturers, their profit method is similar to that in a monopoly platform, so the manufacturers' optimal profit $\pi_{m}^{* *}$ is:

$$
\frac{m^{2} \beta+2 \alpha^{2} \rho+\beta \rho(2 \beta+\rho) C_{m}^{2}-2 m \beta \rho C_{r}+\beta \rho^{2} C_{r}^{2}+2 \beta \rho C_{m}\left(m-2 \alpha-\rho C_{r}\right)}{8 \beta \rho}
$$

and the optimal profit of a closed-loop supply chain is:

$$
\begin{aligned}
& \frac{T_{b} T_{s}-\theta_{b}+\theta_{s}+\delta_{b} \omega_{b}-\delta_{s} \omega_{s}-\left(\theta_{s}-\delta_{b} \omega_{b}\right)\left(\theta_{b}-\delta_{s} \omega_{s}\right)}{4 T_{s}} \\
& -\frac{t_{s}\left(\theta_{b}-\theta_{s}+\delta_{b} \omega_{b}-\delta_{s} \omega_{s}\right)\left(\theta_{b}+\theta_{s}+\delta_{b} \omega_{b}+\delta_{s} \omega_{s}\right)+2\left(4 h T_{s}-t_{b}\left(T_{b} T_{s}+\theta_{b}-\theta_{s}+\delta_{b} \omega_{b}-\delta_{s} \omega_{s}-\left(\theta_{s}-\delta_{b} \omega_{b}\right)\left(\theta_{b}-\delta_{s} \omega_{s}\right)\right)\right)}{16 T_{s}}
\end{aligned}
$$

Proposition 5. $P_{b}$ shows a downward trend, while $P_{s}$ shows an upward trend, with the increase of $\theta_{b}$. As $\theta_{s}$ increases, $P_{s}$ shows a downward trend, while $P_{b}$ shows an upward trend. The platform profit and total profit of a closed-loop supply chain are both positively correlated with $\theta_{b}$ and $\theta_{s}$.

Proposition 5 shows that when the inter-group network externalities of one of the competing platforms increase, the platform's pricing for that party will decrease, while the pricing for the other party will increase. In practice, this is a unique phenomenon where two-sided platforms set high prices for users on one side to subsidize users on the other side, which is also a subsidy strategy adopted by the platform. Platforms with strong inter-group network externalities have a stronger positive feedback effect, which increases the overall profit of the platform and the supply chain in the long run.

Proposition 6. As $\omega_{b}$ and $\omega_{s}$ increase, the prices charged by competing platforms to consumers and manufacturers decrease.

Propositions 6 and 3 of a monopoly platform are roughly similar, but in the competing market structure the platform loses the "dominance" advantage of the monopoly platform, due to the pressure of competition; in practice, often the monopoly platform attaches importance to the sensitivity of two-sided users to wait times, so the platform should, through technology upgrades or techniques, 
provide value-added services to increase the match efficiency and form its own advantage barrier, thus keeping the competing advantage and profit advantage.

\section{Numerical Simulation}

In the above section, theoretical models under different market structures with different ownership structures are studied, the equilibrium solutions under different circumstances are analyzed, and some management experience and inspiration are obtained. First, in this section, the sensitivity analysis method is used to analyze the effects of inter-group network externalities $\theta_{b}, \theta_{s}$, the time sensitivity coefficient $\omega_{s}, \omega_{b}$ and the differentiation of service $T_{b}, T_{s}$ on the pricing and profit of the recycling platform. Then, numerical examples are used to further analyze the pricing and profitability of platforms and supply chains. In addition, we have studied the theoretical researches related to this paper $[7,21]$, combined with the relevant data of manufacturing and remanufacturing of computer main processor cases in DaFeng which is an "Internet +" recycling platform in China, and the data related to sensitivity analysis in the operation of the DaFeng platform so as to better analyze and elaborate the conclusions and management inspiration. By combining theoretical research with a realistic background, we suppose $\theta_{b}=\theta_{s}=0.85, \mu=0.6, \Upsilon=0.6, \delta_{s}=\delta_{b}=0.5, t_{s}=t_{b}=5, \omega_{s}=\omega_{b}=0.3$, $\varphi_{b}=\varphi_{s}=0.7, C_{m}=10, C_{r}=5, \alpha=100, \beta=20, m=80, \rho=10$.

\subsection{Numerical Analysis of a Monopoly Platform}

For monopolistic platforms, this paper considers the influence of inter-group network externalities, matching efficiency and time sensitivity factors on platform pricing and profitability. The sensitivity analysis of these three factors can be found below.

\subsubsection{Inter-Group Network Externalities}

As seen in Figure $3 a, b$, the service prices of the platform for consumers and manufacturers are negatively correlated with the inter-group network externalities of both parties, and when the inter-group network externalities strengthen gradually, the scale effect will also increase, so the platform will impose price subsidies to both sides, reduce pricing on both sides. Therefore, as can be seen from Figure $3 c$,d, with the gradual enhancement of inter-group network externalities, the platform will show negative profit growth over a period of time, but when the inter-group network externalities rise to a certain extent, the user scale will expand and the profit will increase. As for manufacturers, when the platform reduces its charges, their profits increase. Therefore, the overall profit of the closed-loop supply chain system first decreases and then increases. The simulation showed that the profit change of the closed-loop supply chain is similar to that of the platform.

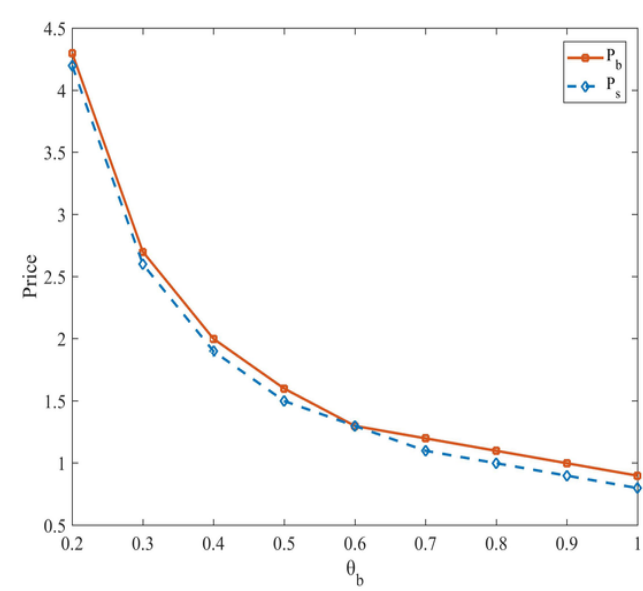

(a)

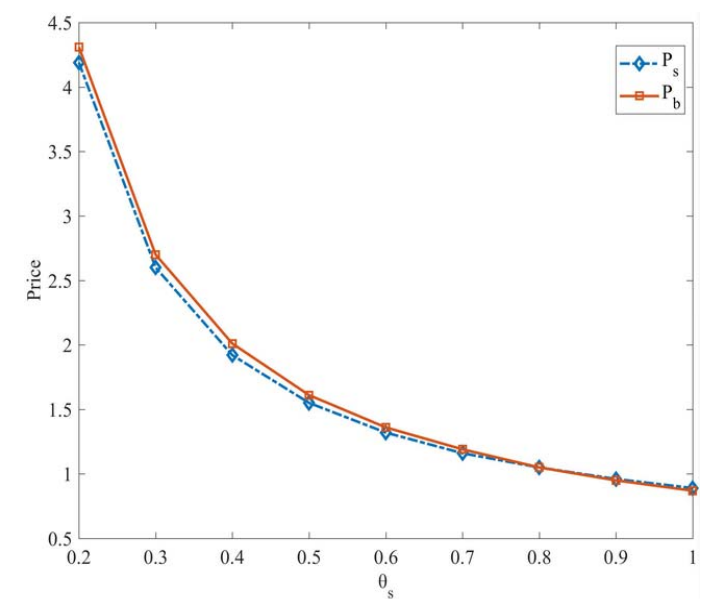

(b)

Figure 3. Cont. 


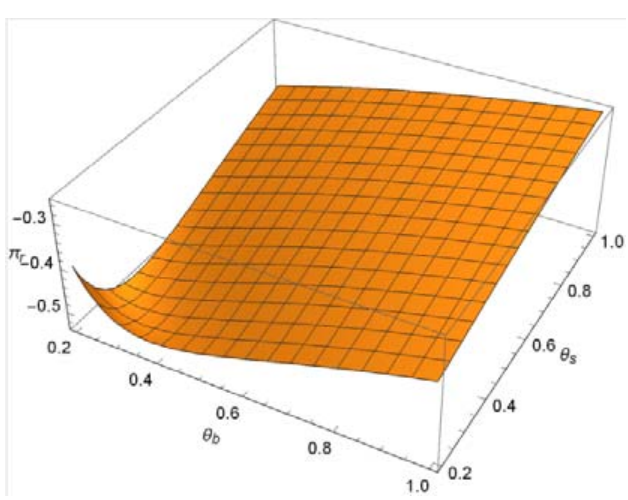

(c)

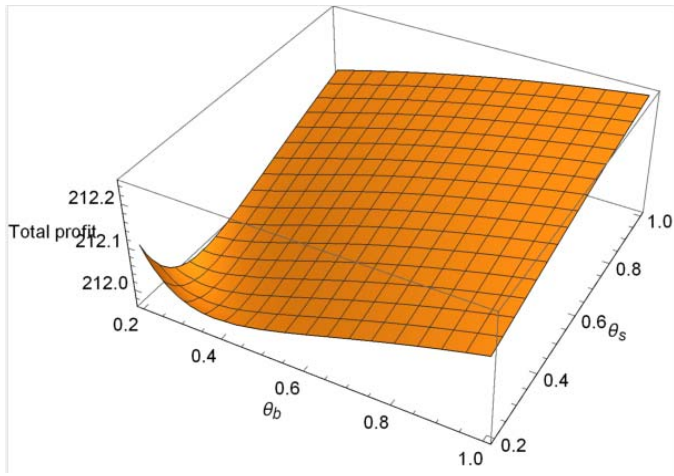

(d)

Figure 3. The impact of inter-group network externalities on monopoly platform decisions: (a) The impact of inter-group network externality $\theta_{b}$ on prices $P_{s}, P_{b} ;(\mathbf{b})$ The impact of inter-group network externality $\theta_{s}$ on prices $P_{s}, P_{b} ;$ (c) The impact of inter-group network externalities $\theta_{b}, \theta_{s}$ on the profit of the platform; (d) The impact of inter-group network externalities $\theta_{b}, \theta_{s}$ on the profit of the closed-loop supply chain.

\subsubsection{Time Sensitivity Coefficient and Matching Efficiency}

As can be seen from Figure 4, as consumers and manufacturers become more sensitive to wait times, the pricing of both sides of the platform will decrease accordingly. This is because when consumers and manufacturers become more sensitive to the length of wait times, they will put forward higher requirements on the matching efficiency of the platform, thus forming a positive incentive effect on the platform, innovating the platform to use a method for improving the technical level and price subsidies to attract more potential customers. In the short term, there will be a certain decline in profits, but in the long run, platforms enhancing the efficiency of matching two-sided users can bring lasting benefits. This is roughly similar to the influence of inter-group network externalities in Section 5.1.1 on profit changes.

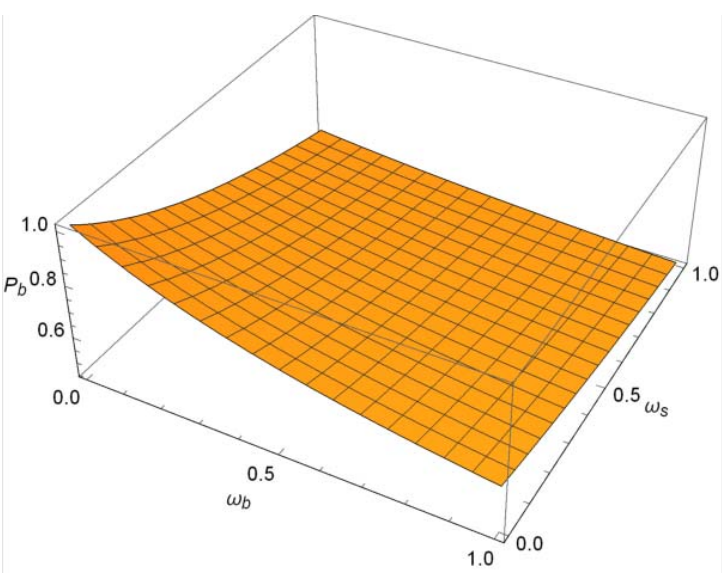

(a)

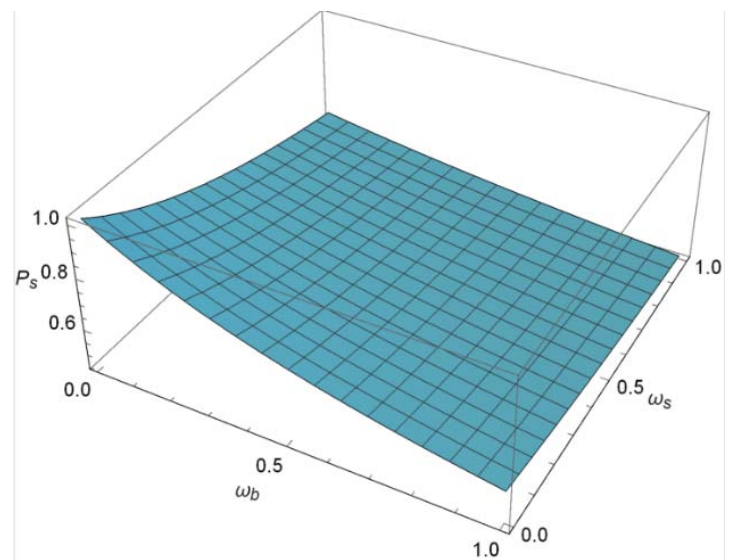

(b)

Figure 4. Impact of matching efficiency on monopoly platform decision-making: (a) The impact of time sensitivity coefficients $\omega_{s}, \omega_{b}$ on price $P_{b} ;(\mathbf{b})$ The impact of time sensitivity coefficients $\omega_{s}, \omega_{b}$ on price $P_{s}$.

\subsection{Numerical Analysis of Competing Platforms}

For duopolistic competing platforms, this paper considers the influence of differentiation of service, matching efficiency, and time sensitivity on platform pricing and profit. The sensitivity of these three factors is studied below. 


\subsubsection{Differentiation of Service}

As can be seen from Figure $5 a, b$, with the improvement of platform service, the recycling platform will increase the collection of service fees for single-homing manufacturers but will have no impact on multi-homing consumers. The improvement of the differentiation of service means that the higher the conversion cost, the more likely manufacturers are to choose platforms with highly differentiated products and services, competing advantages, and maximized profits to join the platform, and the platform will also increase the service fees charged by the single-homing manufacturers due to the upgrade of services. However, due to the low loyalty of multi-homing users, the differentiation of service has little impact on them. As can be seen from Figure $5 c, d$, the platform's equilibrium income is proportional to the differentiation of service. When platforms choose differential operation, they will promote equilibrium income. However, due to technology and product upgrades, there will be a huge initial investment in the enterprise start-up period, and manufacturers' pay will increase; therefore, the closed-loop supply chain's overall profits will fall slightly. This has a certain management implication for enterprises: when platform enterprises choose a differentiated strategy for operation, they will form certain competing advantages so that they can charge higher service fees from two-sided users to obtain higher profits. In addition, in order to maintain their market share and competing position, platforms must adopt differentiated service operation modes in order to avoid homogeneous competition.

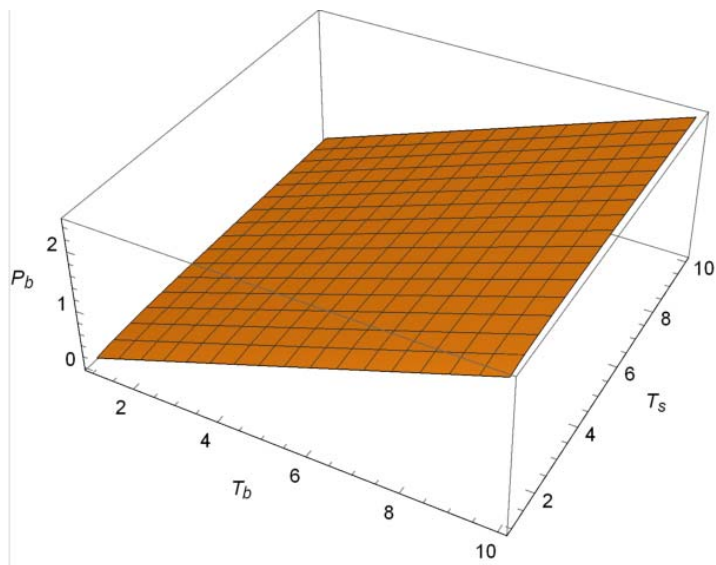

(a)

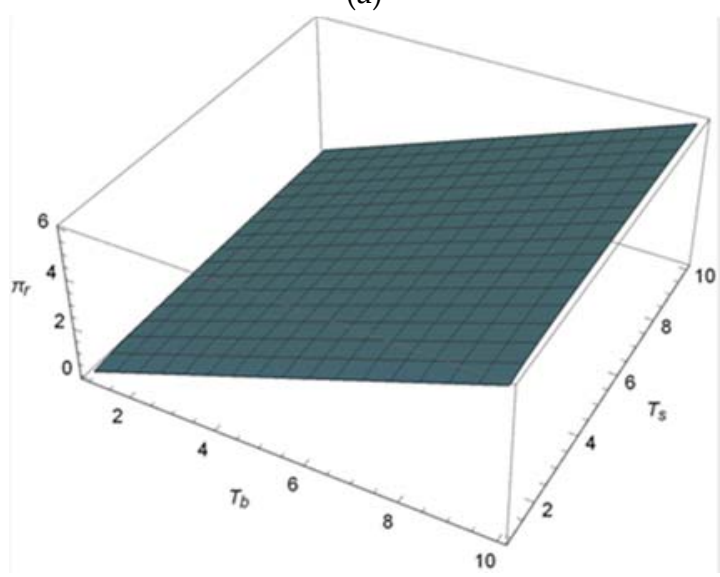

(c)

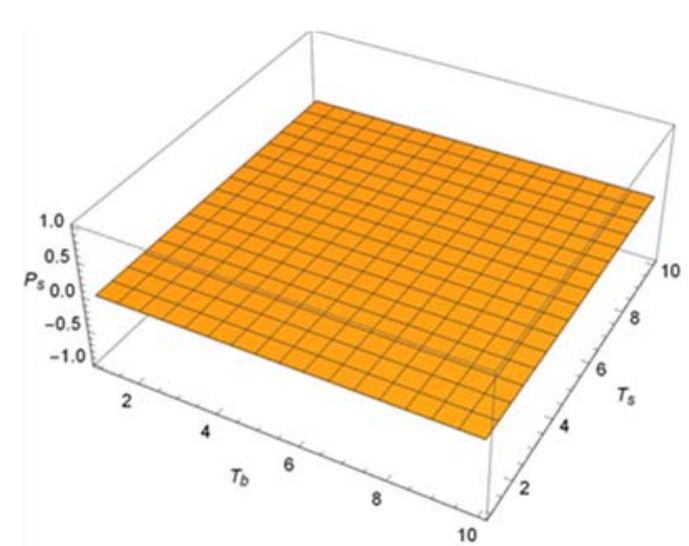

(b)

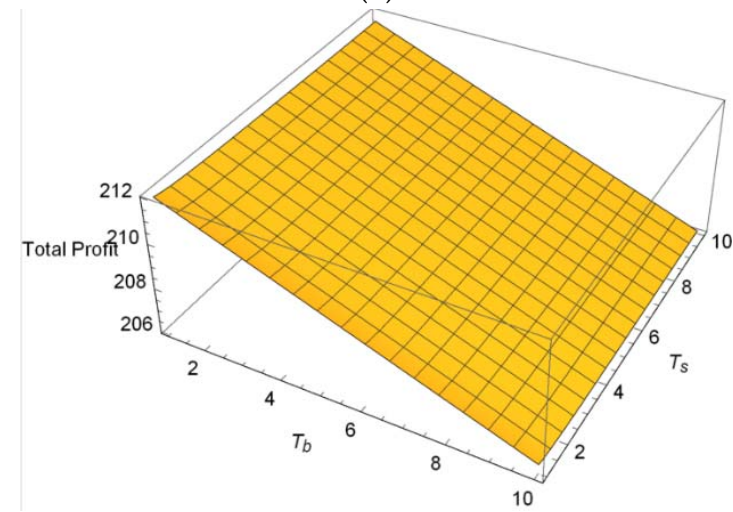

(d)

Figure 5. Influence of differentiation of service on the decision-making of competing platforms: (a) The impact of differentiation of service $T_{b}, T_{s}$ on price $P_{b} ;(\mathbf{b})$ The impact of differentiation of service $T_{b}, T_{s}$ on price $P_{s} ;(\mathbf{c})$ he impact of differentiation of service $T_{b}, T_{s}$ on the profit of the platform; (d) The impact of differentiation of service $T_{b}, T_{s}$ on the profit of the closed-loop supply chain. 


\subsubsection{Inter-Group Network Externalities}

As can be seen from Figure $6 a, b$, when there are two competing recycling platforms, they have equal equilibrium pricing for consumers and manufacturers. Moreover, the pricing of the platform for consumers and manufacturers is negatively correlated with their respective inter-group network externalities, while positively correlated with each other's inter-group network externalities. This is because when the inter-group network externalities of one party gradually increase, resulting in scale effects, the platform will subsidize the price of that party. As for the other party, because the platform needs to make profits, it will often charge a higher price to the other party in order to obtain the subsidy amount. This is the difference between the pricing of competing platforms and that of monopoly platforms, and it is also a unique phenomenon of two-sided markets.

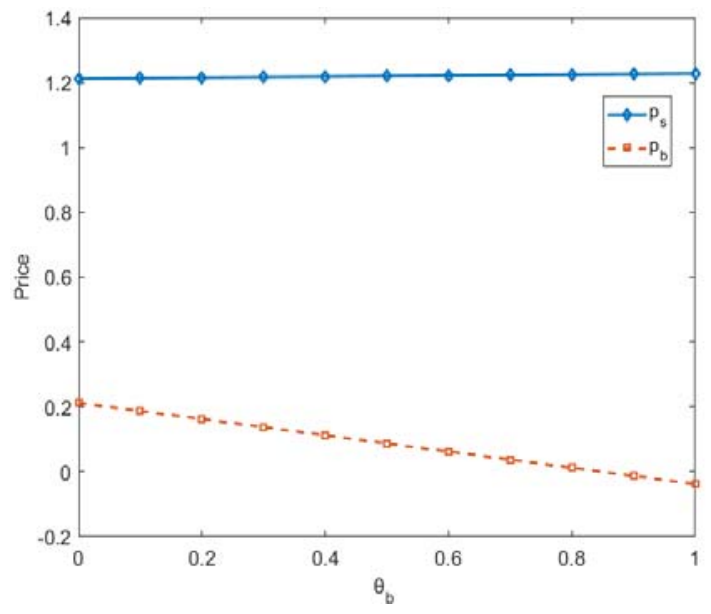

(a)

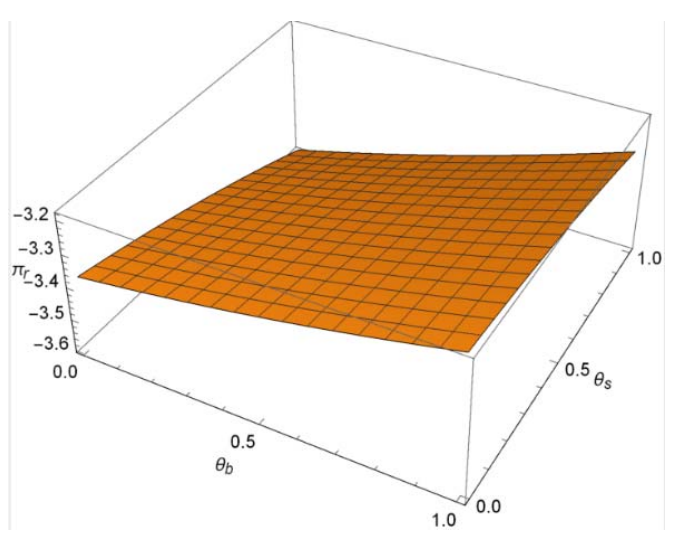

(c)

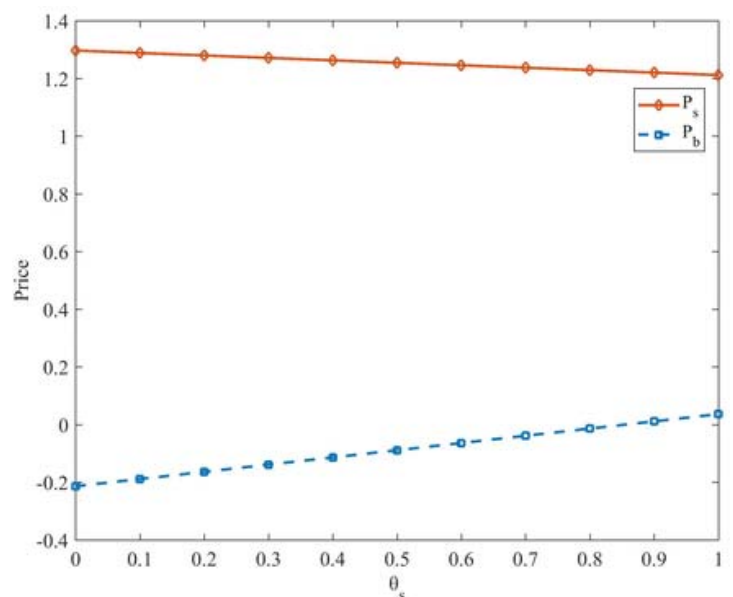

(b)

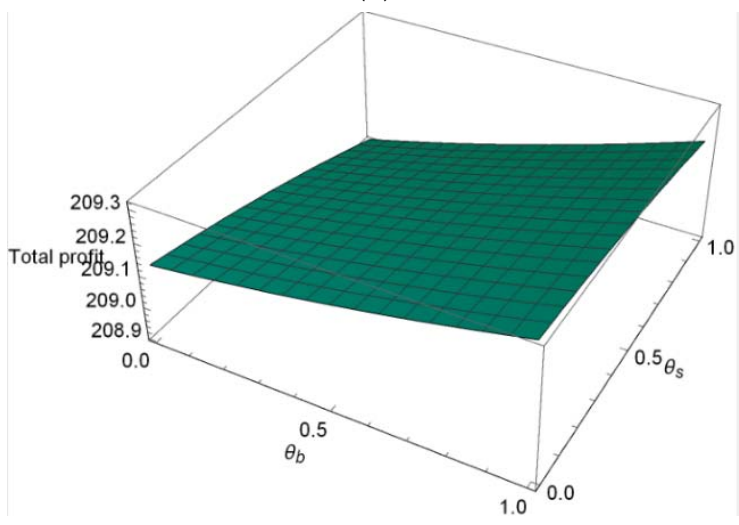

(d)

Figure 6. Impact of inter-group network externalities on competing platform decision-making: (a) The impact of inter-group network externality $\theta_{b}$ on prices $P_{s}, P_{b} ;(\mathbf{b})$ The impact of inter-group network externality $\theta_{s}$ on prices $P_{s}, P_{b} ;$ (c) The impact of inter-group network externalities $\theta_{b}, \theta_{s}$ on the profit of the platform; (d) The impact of inter-group network externalities $\theta_{b}, \theta_{s}$ on the profit of the closed-loop supply chain.

From Figure $6 c, d$ it can be seen that the platform of the equilibrium yield was positively correlated with both sides of the inter-group network externalities, even at the beginning of the platform operation due to the huge initial investment being likely to make profits negative, but that profits are rising all the time. This shows that for profits from the power of the platform to the closed-loop supply chain system as a whole, inter-group network externalities will improve profit growth. 


\subsubsection{Time Sensitivity Coefficient and Matching Efficiency}

As can be seen from Figure 7, similar to monopoly platforms, the pricing of platforms for both sides and the time sensitivity coefficient of both sides are negatively correlated. The graph of the impact of inter-group network externalities on profit changes is similar to that in Section 5.2.2. Thus, it can be seen that whether it is a monopoly platform or a competitive platform, the sensitivity of users to time and the matching efficiency of the platform have a significant impact on the pricing and long-term development of the platform. For a platform enterprise, attention to the after-sale feedback of two-sided users is indispensable. Also, these platforms are advised to investigate the sensitive degree of matching time and use the technology upgrading and resource allocation methods to improve the matching efficiency of platforms for two-sided users, thus raising platform credibility and comprehensive strength.

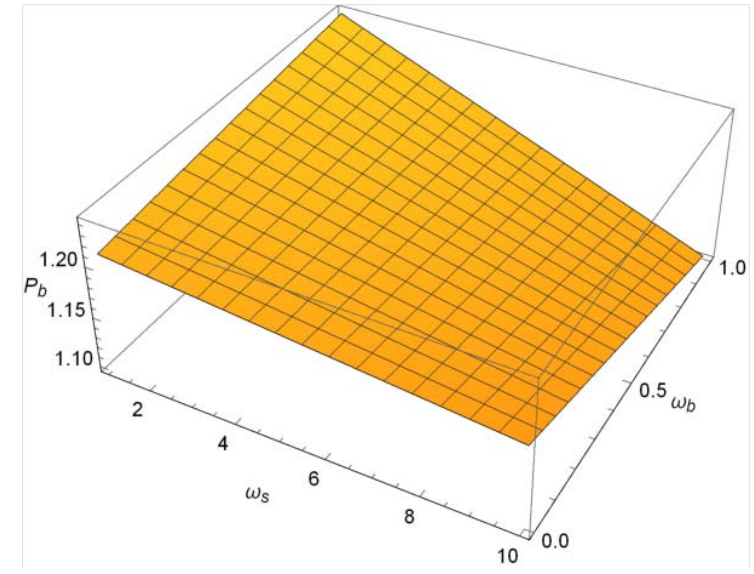

(a)

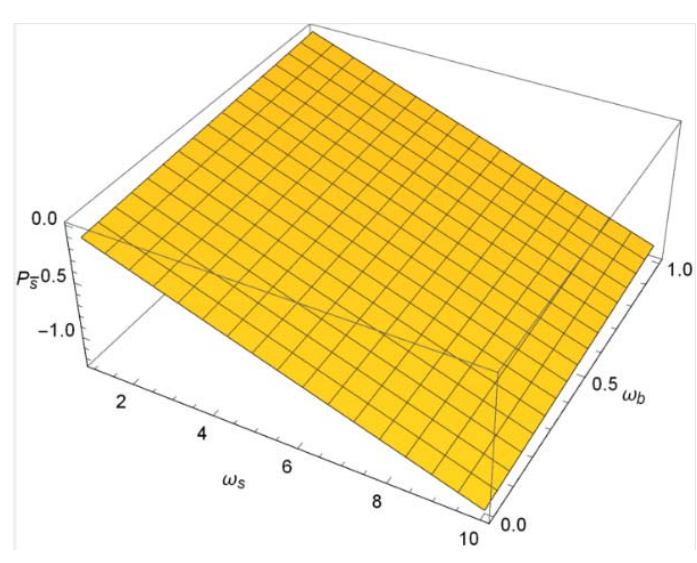

(b)

Figure 7. Impact of matching efficiency on the decision-making of competing platforms: (a) The impact of time sensitivity coefficients $\omega_{s}, \omega_{b}$ on price $P_{b} ;(\mathbf{b})$ The impact of time sensitivity coefficients $\omega_{s}, \omega_{b}$ on price $P_{S}$.

\section{Conclusions}

This paper studied the price structure and profitability of recycling platforms (mainly online platforms) under the "Internet + " recycling mode. Through the introduction of inter-group network externalities, matching efficiency, and differentiation of service of recycling platforms, the pricing structure and scale of two-sided users and the profits of monopolistic and competing platforms were studied. At the same time, the pricing and profit of the supply chain system were discussed. The conclusions are as follows:

(1) The strength of inter-group network externalities is an important factor that determines whether two-sided platforms can take the lead in the market or break through the market barrier. It is also one of the important influencing factors in two-sided markets. In monopolistic platforms, the enhancement of inter-group network externalities will reduce the pricing of the platform for consumers and manufacturers, and make the platform's equilibrium profit decline for a period of time before profits increase steadily. In a competing platform where consumers are multi-homing and manufacturers are single-homing, the enhancement of the inter-group network externalities of one party will reduce the platform's pricing for that party, while raising the price for the other party. Such a practice of subsidizing the other party by setting a high price is also a common phenomenon in two-sided markets. According to this conclusion, we can see that although the emerging recycling platform is different from the traditional way of recycling, the user is still the most important as the core of the recycling process. Therefore, platform enterprises should 
implement a low pricing strategy for users at the beginning and appropriately expand the user scale by subsidizing users, so as to improve the scale effect, attract more manufacturers to join the platform and buy electronic waste, and increase the platform's influence. In addition, the total profit of the closed-loop supply chain also increases with the enhancement of inter-group network externalities, indicating that the increase of inter-group network externalities promotes the long-term development of both the supply chain and the platform. By comparing the influence of inter-group network externalities on monopolistic and duopolistic competing platforms, the following conclusions were obtained. First, the pricing of two-sided platforms for consumers and manufacturers is negatively correlated with the strength of their respective inter-group network externalities, which is a result shared by the two types of platform. As for the relationship between one party's pricing and another party's inter-group network externalities, there is still a negative correlation between them in monopoly platforms and a positive correlation between them in competing platforms. Second, in terms of management, two-sided platforms should give full play to the positive feedback role of inter-group network externalities, so as to expand the user scale of two-sided platforms, form a stable customer flow, and occupy a dominant position in the market.

(2) For emerging online recycling platforms, the efficiency with which both consumers and manufacturers can be matched is one of the most important factors in a platform's long-term operation and market share. Because of their low loyalty, consumers tend to choose multi-homing to a platform, and the matching efficiency of a platform is the key factor for increasing users' secondary usage rate of the platform. This paper considered the time sensitivity factor of consumers and manufacturers waiting for matching. With the increase of the time sensitivity coefficient, both monopolistic platforms and competing platforms chose to lower the price for users and manufacturers to subsidize both sides. Therefore, the equilibrium profit of the platform fell in the short term. However, in the long term, as customers put forward higher requirements for matching efficiency, the platform had to improve the matching efficiency through technical means and other methods. Therefore, a platform with a high long-term matching efficiency will attract a large number of users, occupy most of the market share, and see its equilibrium income increase accordingly.

(3) The improvement of a product or service has a positive feedback effect on the pricing and profitability of "Internet + " two-sided platforms. There is an important relationship between the pricing of bilateral platforms for single-homing manufacturers and the degree of service differentiation in competing markets. The improvement of the degree of service differentiation will increase the pricing of the platform to manufacturers, and the balanced income of the platform will also be improved. The overall income of the closed-loop supply chain will increase as well, while the pricing of the platform for users will remain almost unchanged. This brings us to the management implication that platform enterprises should improve the degree of service differentiation to increase their competitiveness and create services with their own characteristics. In this way, platforms can attract more users and manufacturers to join them, thus increasing the scale of users and boosting profits.

Author Contributions: Conceptualization, X.Z. and W.L.; Methodology, W.L.; Software, W.L.; Formal Analysis, W.L.; Resources, X.Z.; Validation, W.L.; Visualization, W.L.; and Project Administration, W.L. All authors have read and agreed to the published version of the manuscript.

Funding: This research was funded by the Humanity and Social Science Youth Foundation of the Ministry of Education in China (Grant Number 19YJC630240) and the Practice Innovation Training Program of College Students in Jiangsu Province (Grant Number 201910300045Z).

Acknowledgments: This paper received administrative and technical support from the China Institute of Manufacturing Development. Meanwhile, the authors would like to thank the anonymous reviewers for their valuable comments and suggestions to improve the quality of the paper.

Conflicts of Interest: The authors declare no conflict of interest. 


\section{References}

1. Thompson, S. Electronic waste and its regulation. Recycling of Materials and Energy from Urban. Wastes: A Volume in the Encyclopedia of Sustainability Science and Technology, 2nd ed.; Themelis, N.J., Bourtsalas, A.C., Eds.; Springer: New York, NY, USA, 2019; pp. 119-124.

2. He, Y.; Xu, Z. Recycling gold and copper from waste printed circuit boards using chlorination process. RSC Adv. 2015, 5, 8957-8964. [CrossRef]

3. Hagiu, A. Two-Sided Platforms: Pricing and Social Efficiency. Research Institue of Econony, Trade and Industry: Tokio, Japan, 2004. Available online: https://www.rieti.go.jp/jp/publications/dp/04e035.pdf (accessed on 28 January 2020).

4. Caillaud, B.; Jullien, B. Chicken \& egg: Competition among intermediation service providers. RAND J. Econ. 2003, 34, 309-328.

5. Armstrong, M. Competition in two-sided markets. RAND J. Econ. 2006, 37, 668-691. [CrossRef]

6. Rochet, J.C.; Tirole, J. Platform competition in two-sided markets. J. Eur. Econ. Assoc. 2003, 1, 990-1029. [CrossRef]

7. Zhang, K.; Dong, Y.S. User operation cost and pricing strategy selection in bilateral platforms. J. Industrial Engineering and Engineering Management 2019, 153-161. [CrossRef]

8. Savaskan, R.C.; Bhattacharya, S.; van Wassenhove, L.N. Closed-Loop Supply Chain Models with Product Remanufacturing. Manag. Sci. 2004, 50, 239-252. [CrossRef]

9. Zhao, J.; Wang, C.; Xu, L. Decision for pricing, service, and recycling of closed-loop supply chains considering different remanufacturing roles and technology authorizations. Comput. Ind. Eng. 2019, 132, 59-73. [CrossRef]

10. Li, Y.; Feng, L.; Govindan, K.; Xu, F. Effects of a secondary market on original equipment manufactures' pricing, trade-in remanufacturing, and entry decisions. Eur. J. Oper. Res. 2019, 279, 751-766. [CrossRef]

11. Kabul, M.O.; Parlakturk, A.K. The value of commitments when selling to strategic consumers: A supply chain perspective. Manag. Sci. 2019. [CrossRef]

12. Yan, L.; Xinyi, L.; Qingli, D. Research on hierarchical pricing based on quality of used parts and "trade-in" subsidy. Chin. J. Manag. Sci. 2019, 27, 131-142.

13. Zhu, X.; Wang, J.; Tang, J. Recycling pricing and coordination of WEEE dual-channel closed-loop supply chain considering consumers' bargaining. Int. J. Environ. Res. Public Health 2017, 14, 1578. [CrossRef] [PubMed]

14. Awasthi, A.K.; Li, J. Management of electrical and electronic waste: A comparative evaluation of China and India. Renew. Sustain. Energy Rev. 2017, 76, 434-447. [CrossRef]

15. Islam, M.T.; Huda, N. Assessing the recycling potential of "unregulated" e-waste in Australia. Resour. Conserv. Recy. 2020, 152. [CrossRef]

16. Gao, M.; Liao, M.L. Model analysis of e-waste recycling under government subsidies. Ecol. Econ. 2019, 8, 17.

17. Wang, W.B.; Ding, J.F.; Da, Q.L. Cost-profit sharing contract for a closed-loop supply chain under reward-penalty mechanism. Control Decis. 2019, 34, 843-850.

18. Wang, X.V.; Wang, L. Digital twin-based WEEE recycling, recovery and remanufacturing in the background of Industry 4.0. Int. J. Prod. Res. 2019, 57, 3892-3902. [CrossRef]

19. Zha, L.; Yin, Y.; Yang, H. Economic analysis of ride-sourcing markets. Transp. Res. C-Emer. 2016, 71, $249-266$. [CrossRef]

20. Kung, L.-C.; Zhong, G.-Y. The optimal pricing strategy for two-sided platform delivery in the sharing economy. Transport Res. E-Log. 2017, 101, 1-12. [CrossRef]

21. Atasu, A.; Sarvary, M.; Van Wassenhove, L.N. Remanufacturing as a marketing strategy. Manag. Sci. 2008, 54, 1731-1746. [CrossRef]

(C) 2020 by the authors. Licensee MDPI, Basel, Switzerland. This article is an open access article distributed under the terms and conditions of the Creative Commons Attribution (CC BY) license (http://creativecommons.org/licenses/by/4.0/). 